\title{
Ethical issues when non-paternity is an incidental finding
}

\begin{abstract}
Biological non-paternity is sometimes discovered incidentally as a result of genetic testing for other medical purposes. Providers may then struggle when deciding what they should do. This question is profoundly important because providers' disclosing this information may be most destructive to families, and especially to children. This piece will review major concerns likely to arise in these cases. It will also present several different approaches care providers have taken in an attempt to resolve this dilemma both before and after this finding is discerned. The author will suggest that a framework not commonly applied to such questions, the Ethics of Care, may be particularly helpful to providers facing this question.
\end{abstract}

Keywords: non-paternity, genetics, ethics, families, children, incidental
Volume 7 Issue I - 202I

\section{Edmund G Howe}

Professor of Psychiatry and Director of Programs in Medical Ethics at the Uniformed Services University of the Health Sciences in Bethesda, USA

Correspondence: Edmund G Howe, MD, JD, is Professor of Psychiatry and Director of Programs in Medical Ethics at the Uniformed Services University of the Health Sciences in Bethesda, Maryland, USA, Email Edmund.howe@usuhs.edu

Received: November 172020 | Published: January 21, 2021

\section{Introduction}

An ethical issue that may cause medical providers extreme anguish is what to do when genetic testing shows non-paternity as an incidental finding. ${ }^{1,2,3}$ The rate of this misattributed parentage is estimated to be between $1 \%$ to $10 \%$ of all births. ${ }^{4}$ The discovery of non-parentage may, however, be but a small subset of this group. ${ }^{5}$ Still, when this outcome is discerned and disclosed, the result can be devastating to the entire family. The child, other children, and both parents may be severely and permanently harmed. This disclosure may also jeopardize mothers' safety, result in child support being withdrawn, result in family members' losing inheritance, and cause bitter custody disputes. ${ }^{5}$ As one provider has said, this disclosure "will clearly change the family's basic premises of membership and identity forever"6

The value conflicts this poses for providers are exceptionally difficult. Competing values are mutually exclusive so the price paid is inevitably high. ${ }^{7-12}$ Consequently, providers' views on what they should do when this question arises have differed. Some have favored, for example, never telling parents this outcome. Others spell out what they will do in advance. ${ }^{13}$ Still others tailor their responses to families' different needs. In this piece I primarily shall discuss different ways in which providers may respond. First, I shall consider core concerns that arise in most cases. ${ }^{12-14}$ Second, I shall discuss contrasting approaches providers take and the major pros and cons of each. Third, I shall discuss the Ethics of Care, an ethical framework often not considered in these discussions. ${ }^{15}$ This framework emphasizes the relationships between people. I shall discuss why it might warrant greater moral weight than it has been given in the past.

\section{General considerations}

\section{Uniform approaches versus tailoring}

A core, overarching question is whether providers' practices should be uniform or tailored to each families' needs. A uniform approach limits the degree to which outcomes can differ due to factors reflecting providers' biases. ${ }^{16-18}$ Providers seeking uniformity may, for example, tell parents in advance that they will not give them incidental information unless it has medical relevance for their child. ${ }^{19}$ The result will be more just. All parents and their children will be treated equally.
Providers' tailoring their interventions to each family's individual needs will, on the other hand, allow providers to take more into account the idiosyncratic needs of each family. ${ }^{20}$ This should benefit each family to a greater extent.

\section{Who should decide}

What providers decide may depend on who makes this decision. What they do may be decided by them, the institution for whom they work, or parents. Providers may believe that their medical knowledge and experience gives them greater ethical expertise than parents. This may or may not be the case. Providers, in any case, may, whenever possible, give moral weight also to parents' views. ${ }^{19}$

\section{Parents' capacity to accept non-biological parenthood}

Providers may hope that if parents learn that they are not their children's biological parent, they will not be significantly affected. They may hope, for instance, that fathers - who almost always are those affected - will love these children no less, but as much as they would if they had adopted them initially. ${ }^{21}$ Unfortunately, this often isn't the case. Rather, the fathers' relationships with these children may be destroyed. Providers may hope, alternatively, that when fathers are unable to accept that they are not their children's biological fathers, they can overcome this through counseling. Unfortunately, this too may not be the case. Providers may ask parents in advance whether they would want these results. Here, fathers and mothers may believe that their finding out that they are not their child's biological parent will not make a difference when it will. Providers' respecting parents' autonomy by doing what they want may, though, be best in any case.

\section{How mothers may be affected}

Mothers may also find out that they are not biological parents. This may come about when children are born as a result of in vitro fertilization (IVF). Mistakes in IVF procedures may be made. ${ }^{13}$ With IVF, it may then also benefit parents for providers to anticipate these incidental findings and discuss this with parents in advance. Providers' informing these parents that a mistake could occur with IVF may, on the other hand, scare them. Thus, due to the most remote chance that this could occur, it may be better here to not so inform them. 


\section{Parents' concerns in other contexts}

Parents may have concerns about the effects of genetic information on their relationship with their children also in other contexts. An example occurred when a transgender parent did not want his child to know that after he had given his child birth, he changed his gender. He feared that his child might find this out from in some way later viewing his father's medical records. Here, even if this wouldn't occur, he still may have had this underlying concern. Providers' options may be limited in what they can do to relieve parents' concerns in some instances. Then, they refer these parents to counselors in the hope that this might help them to reduce their fear. These parents too might decide, as a result of this counseling, to share information about themselves with their children that they wanted to keep secret, after all.

\section{Competing, mutually exclusive values}

Providers usually see themselves as obligated to prioritize their patients' medical needs. These needs include families' emotional needs. There are, however, legal obligations that providers may see as requiring them to place other duties above families' needs. Examples are their acquiring incidental genetic findings that suggest that criminal conduct or incest has occurred. Genetic findings may show, for example, that an adult has had sex with a minor. In regard to incest, these findings may show that two persons, closely related biologically, have had a child. The closeness of this relationship, however, may be of different degrees. Thus, in this instance, providers may have greater flexibility and thus be more able to use their discretion. ${ }^{15}$

\section{The relevance of culture}

Parents' culture may also affect what providers can and should disclose. In some cultures, for example, a woman convicted of consented infidelity may face most severe adverse consequences. ${ }^{22-25}$ Providers should keep in mind, though, that even when parents share the same culture, as when they are next door neighbors, their views may wholly differ as much as they would if they were from different cultures. Providers must initially then explore both parents' views fully and separately so that they do not inadvertently favor one parent's views over the other's, by not exploring each to the degree that they could and should. If two parents have irresolvable differences, mediators or, again, counselors may help.

\section{Different approaches}

\section{Leaving the choice up to mothers}

Perhaps the most common approach providers take is, when possible medically, to inform, first and only, mothers of this risk of discovering non-paternity. This can occur if these mothers initially come in alone. Providers then can leave it up to these mothers to decide whether anyone will be tested and if so, who this will be..$^{20}$ If the mother suspects that her child's father may not be the biological father, she may choose to not ask this father to be tested. ${ }^{19}$ This respects her autonomy and may be most beneficial to all. Providers may be willing to do this, however, only if there are no risks of adverse medical consequences to anyone. This approach also allows the provider to sustain a more positive relationship with the mother since it allows her to decide. ${ }^{15}$ The mother, too, then, may not know or even ever know whether her husband - or another former partner - is their child's biological father. This may be what she would want. The provider might, then, take initiative to explore this with her before she decides. Providers may not want to offer mothers this decision- making option on the ground that the mother chose to engage in what they see as an indiscretion. They may believe that she should bear this decision's consequences. This view is for several reasons ethically problematic. Chief among these problems is that the consequences may be profoundly destructive to the child and family. This harm may far outweigh all other considerations. The provider, also, has no ethical basis for taking on this judging role.

\section{Insisting that mothers tell fathers}

Another approach, quite the opposite of the one above, may occur after providers discover non-paternity incidentally. These providers may then tell these mothers that they must tell these fathers, as, for instance, within a week. Further, they may then say that they will then check and if these mothers have not told the father by then, these providers will.

Providers may do this for several reasons. They may think that those in the medical profession should not keep secrets. ${ }^{14,17,26,27}$ They may think that fathers have an absolute right to know. They may also use these two above reasons to justify their imposing their personal view that the mother should be punished for her past indiscretion, as I noted above. They may do this without their knowing that they are using these reasons to rationalize their imposition of their morally unjustifiable personal bias.

\section{Telling no one}

A third approach is for providers to inform both parents initially that any information they find incidentally they will not disclose unless it is medically relevant. ${ }^{13}$ This practice of total non-disclosure has been used to protect family members' relationships by keeping them intact in other contexts. Transplant centers, for example, may inform family members before a transplant is carried out that if for some reason the transplant is cancelled, the staff will not tell the family why. A reason for this policy is that parents and others may refuse to donate their kidney at the last minute. There may be other reasons for canceling the transplant than these parents' own interest, but the staff's not telling the family will prevent the family from a possibly devastatingly effect, just as may occur after the disclosure of non-paternity. This transplant policy is controversial. It illustrates, however, another instance in which medical staff may agree to keep to themselves a family secret.

\section{Not telling parents that non-paternity can be discerned}

A fourth approach sometimes carried out is for providers to not tell either parent that genetic testing can produce this incidental finding. ${ }^{28}$ Some parents may not know this unless their provider tells them. They may not know that genetic testing conducted for an entirely different medical reason could also reveal non-paternity. If, though, the provider tells such parents this such that they learn this for the first time, they -who almost always will be fathers - may, in response, want then to be tested. They may seek this out even at another institution. Then, the same harmful outcomes for their family may come about.

\section{Telling parents that mutation is possible or even quite possible}

The finding of non-paternity may be due to a genetic mutation, uncommon though this may be. Fathers found on genetic testing to not be their child's biological father may, though, still be their child's biological fathers. The likelihood of this may depend on the kind of testing being done. Some providers, routinely tell parents this. Some, in addition, go further. They purposefully state that this is more likely 
than it is, because they know that, then, fathers who want to believe that they are the biologically-related fathers may more easily conclude that a mutation has occurred. These providers may stretch this truth that a mutation could occur, for instance, by telling these fathers or both parents that the likelihood of a mutation is "quite possible." 27 Providers saying this furthers the possibility that parents can believe what they want to believe. The capacity of people to believe what they want to believe and to successfully deny what they don't want to believe varies. An example of some people having a greater capacity for denial, commonly seen in the medical community, is pregnant women coming into the emergency room in labor who do not know that they are pregnant. They may believe, for example, that they have a stomach ache. Fathers, in somewhat this same way, may want to believe that a mutation has occurred, though this is highly unlikely. Parents wanting to be more certain may, on the other hand, go on to have more definitive genetic testing..$^{29}$

\section{Asking both parents what together they want}

A sixth approach is to ask both parents what they each would want if non-biological parenthood is incidentally discovered. ${ }^{12}$ Here a first problem is that these partners may not agree. An approach that may be useful in this instance is to ask both parents to try to imagine what they would feel toward their child and each other if in the future they did know and didn't know. They may find that this imaginary exercise helps them get clearer on what they really most want. The father may discover, for instance, that he would still feel the same for his child, just as he would if he had initially adopted this child. As noted earlier, parents may not know how in the future they would respond. Again, counseling may in this instance help. Counseling may, in this instance, also help these parents see what they feel and/or want to continue to be able to feel for each other, as well as what they want to feel and want to be able to feel for their child. They may, for all these reasons, decide to decline being tested. They may discover that their love for each other and their love for their child that they presently have far outweighs what they would gain from knowing whether the father is biologically the father of their child.

\section{The care perspective}

The Care Perspective holds that what is most important to people is likely to be their relationships with other people. Weaver, speaking as an advocate for prioritizing this approach when deciding what to do after findings of genetic non-paternity, states, "More than imposed standards of justice, the ethic of care is grounded in voice and relationships, recognizing the importance of a patient's being listened to carefully and heard with respect. An ethic of care recognizes the need for a physician to be responsive to the patient's interpretation of her inter-connected relationships and the patient's interpretation of informational needs within those relationships. An ethic of care has potential to both inform and advise timing and content of genetic disclosure. ${ }^{15}$ Her practical conclusion is unequivocal. She declares, "A blind standard of physician disclosure should not be seen as best practice. Instead, relationally informed and patient-empowered disclosure should be seen as the best approach." These relationships in this instance involve both parents, the child and, perhaps, also other children. Weaver's adding this additional framework may, for some providers, move them to leave this decision up to mothers as opposed to their telling them that if they won't tell the father, they will.

\section{Conclusion}

When providers incidentally discover non-biological parenthood, this is a crisis. ${ }^{12,19}$ The outcome of what they alone or with the parent or parents decide may profoundly affect children's and these families' lives. This may destroy their relationships with each other. In light of these possibly dire outcomes, providers might consider preventing this harm by nor prioritizing the moral principles of telling the truth and not keeping a secret. ${ }^{4,26}$ Providers' relationships with these mothers or parents may also warrant moral weight..$^{30}$ It is, of course, the children who are most likely to be vulnerable here. Thus, on this ground alone, it may be that providers, above all, should seek to protect these children. ${ }^{31}$ It may be that this ultimate concern should prevail whether or not from even a legal view there may be some who advise other options. ${ }^{32,33}$

\section{Acknowledgments}

The opinions or assertions contained herein are the private views of the author and are not necessarily those of USUHS, or the Department of Defense.

\section{Conflicts of interest}

Author declare that there is no conflict of interest.

\section{Funding}

None.

\section{References}

1. Lincoln P, Syndercombe C. Rates of non-paternity. Lancet 1992;340(8827):1108

2. Greeff J, Erasmus J. Three hundred years of low non-paternity in a human population. Heredity (Edinb). 2015;115(5):396-404.

3. Wertz D, Fletcher J, Mulvihill J. Medical geneticists confront ethical dilemmas: cross-cultural comparisons among 18 nations. Am J Hum Genet. 1990;46(6):1200-1213.

4. Prero M, Strenk M, Garrett J, et al. Disclosure of misattributed paternity. Pediatrics. 2019;143 (6):e20183899.

5. Palmor M, Fiester A. Incidental findings of nonparentage: a case for universal nondisclosure. Pediatrics. 2014;134(1):163-168.

6. Wright L, MacRae S, Gordon D, et al. Disclosure of misattributed paternity: issues involved in the discovery of unsought information. Semin Dial. 2002;15(3):202-206.

7. Wertz D, Fletcher J. Proposed: an international code of ethics for medical genetics. Clin Genet. 1993;44:37-43.

8. Offit K, Groeger E, Turner S, et al. The "duty to warn" a patient's family members about hereditary disease risks. JAMA. 2004;292(12):1469147

9. Hercher L, Jamal L. An old problem in a new age: revisiting the clinical dilemma of misattributed paternity. Appl Transl Genomics. 2016;8:3639.

10. Lucassen A, Parker M. Revealing false paternity: some ethical considerations. Lancet. 2001;357(9261):1033-1035.

11. Ross L. Disclosing misattributed paternity. Bioethics. 1996;10(2):114 130

12. Botkin JR, Belmont JW, Berg JS, et al. Points to consider: ethical, legal, and psychosocial implications of genetic testing in children and adolescents. Am J Hum Genet. 2015;97(1):6-21.

13. Palmor M, Fiester A. Incidental findings of nonparentage: a case for universal nondisclosure. Pediatrics. 2014;134(1):163-168.

14. McAbee G, Sherman J, Davidoff-Feldman B. Physician's duty to warn third parties about the risk of genetic diseases. Pediatrics. 1998;102(pt 1):140-142 
15. Weaver M. The double helix: applying an ethic of care to the duty to warn genetic relatives of genetic information. Bioethics. 2016;30(3):181-187.

16. Ross L. Good ethics requires good science: why transplant programs should not disclose misattributed parentage. Am J Transplant. 2010;10(4):742-746.

17. Ross L, Saal H, David K, et al. Ethical and policy issues in genetic testing and screening of children. Genet Med. 2013;15(3):234-245.

18. Wright C, Parker M, Lucassen A. When genomic medicine reveals misattributed genetic relationships-the debate about disclosure revisited. Genet Med. 2019;21(1):97-101.

19. Lowe G, Pugh J, Kahane G, et al. How should we deal with misattributed paternity? A survey of lay public attitudes. AJOB Empir Bioeth. 2017;8(4):234-242.

20. Chandler J. Incidental findings of nonparentage should be disclosed. Pediatrics. 2015;135(1):e284.

21. Middleton A, Parker M, Wright CF, et al. Empirical research on the ethics of genomic research. Am JMed Genet. 2013;161A(8):2099-2101.

22. Tozzo P, Caenazzo L, Parker M. Discovering misattributed paternity in genetic counselling: different ethical perspectives in two countries. $J$ Med Ethics. 2014;40(3):177-181.

23. Lisker R, Carnevale A, Villa J, et al. Mexican geneticists' opinions on disclosure issues. Clin Genet. 1998;54(4):321-329.

24. Komesaroff PA. Cross-Cultural Issues in Ethics: Context Is Everything: Commentary on "The dilemma of revealing sensitive information on paternity status in Arabian social and cultural contexts. $J$ Bioeth Inq 2012;9:417-418.
25. Adlan A, ten Have $\mathrm{H}$. The dilemma of revealing sensitive information on paternity status in Arabian social and cultural contexts: Telling the truth about paternity in Saudi Arabia. J Bioeth Inq. 2012;9(4):403-409.

26. Committee on Bioethics, Committee on Genetic, American College of Medical Genetics, et al. Ethical and policy issues in genetic testing and screening of children. Pediatrics. 2013;131(3):620-622.

27. Lucast E. Informed consent and the misattributed paternity problem in genetic counseling. Bioethics. 2007;21(1):41-50.

28. Xia D, Zhang C, Lip V, et al. Trio-R: a script for assessing maternity and paternity in trio studies performed on Agilent chromosomal microarrays. BMC Med Inform Decis Mak. 2018;18(1):91.

29. Metz T. Harmonizing global ethics in the future: a proposal to add south and east to west. Journal of Global Ethics. 2014;10(2):146-155.

30. Campbell K. Disclosure of non-paternity. Lancet. 2004;364(9431):327328 .

31. Ginzl D. New law allows genetic testing to administratively determine paternity. BiWeekly Newsletter of the State Bar of Wisconsin. 2020;12(2):1.

32. https://www.wisbar.org/NewsPublications/InsideTrack/Pages/Article. asp $x$ ? Volume $=12 \&$ Issue $=2 \&$ ArticleID $=27439$

33. Blease C, Walker J, DesRoches CM, et al. New U.S. law mandates access to clinical notes: implications for patients and clinicians, annals of internal medicine Ann Intern Med. 2020 